\title{
The effectiveness of an educational intervention
} to improve knowledge and perceptions for reducing organophosphate pesticide exposure among Indonesian and South Australian migrant farmworkers

This article was published in the following Dove Press journal:

Risk Management and Healthcare Policy

19 January 2016

Number of times this article has been viewed

\author{
Suratman Suratman ${ }^{1,2}$ \\ Kirstin E Ross' \\ Kateryna Babina' \\ John William Edwards' \\ 'Health and Environment Group, \\ School of the Environment, Faculty \\ of Science and Engineering, Flinders \\ University, Adelaide, SA, Australia; \\ ${ }^{2} \mathrm{School}$ of Public Health, Faculty of \\ Health Sciences, Jenderal Soedirman \\ University, Kampus Karangwangkal, \\ Purwokerto, Indonesia
}

Background: Farmworkers are at risk of exposure to organophosphate pesticides (OPs). Improvements of knowledge and perceptions about organophosphate (OP) exposure may be of benefit for the reduction in OP exposure.

Purpose: The purpose of this study was to examine the effectiveness of an educational intervention to improve knowledge and perceptions for reducing OP exposure among Indonesian and South Australian (SA) migrant farmworkers.

Methods: This was a quasi-experimental study. The educational intervention used a method of group communication for 30 Indonesian farmworkers and individual communication for seven SA migrant farmworkers. Knowledge and perceptions about OP exposure were measured preintervention and 3 months after the intervention.

Results: Unadjusted intervention effects at follow-up showed statistically significantly improved scores of knowledge (both adverse effects of OPs and self-protection from OP exposure), perceived susceptibility, and perceived barriers among Indonesian farmworkers compared with SA migrant farmworkers. Furthermore, these four significant variables in the unadjusted model and the two other variables (perceived severity and perceived benefits) were statistically significant after being adjusted for the level of education and years working as a farmworker. In contrast, knowledge about adverse effects of OPs was the only variable that was statistically significantly improved among SA migrant farmworkers. The results of this study suggests educational interventions using a method of group communication could be more effective than using individual intervention.

Conclusion: These improvements provide starting points to change health behavior of farmworkers, particularly to reduce OP exposure, both at the workplace and at home.

Keywords: group communication, individual communication, organophosphate pesticide exposure, Indonesian farmworkers, South Australian migrant farmworkers

\section{Introduction}

Organophosphorus pesticides (OPs) are highly toxic and exposure to OPs contributes to mortality and morbidity when their use is poorly controlled. ${ }^{1}$ Farmworkers are at risk of exposure to OPs. There is overwhelming epidemiological evidence that organophosphate (OP) use poses significant health risks if undertaken without safe handling practices. Studies in developing countries ${ }^{2-6}$ and developed countries ${ }^{7-9}$ have demonstrated acute and chronic effects due to OP exposure.
Correspondence: Suratman Suratman Health and Environment Group, School of the Environment, Faculty of Science and Engineering, Flinders University, Sturt Road, Bedford Park, Adelaide, SA 5042, Australia

Tel +6I $434 \mid 4845$ I

Emailsura0018@flinders.edu.au 
A study by $\mathrm{He}^{10}$ in the People's Republic of China showed that as many as $18 \%$ of 6,281 deaths (deaths due to acute pesticide poisoning) were due to occupational pesticide poisoning and $78 \%$ of these cases of pesticide poisoning were due to OP compounds in the year 1993. In addition, a study by Dasgupta et $\mathrm{al}^{5}$ in Vietnam demonstrated that all 190 participant farmworkers had some ill health symptoms after mixing and spraying OP. These symptoms consisted of skin irritation (66\%), headache $(61 \%)$, dizziness (49\%), eye irritation (56\%), and shortness of breath (44\%).

A wide range of measures exist for reducing health risks from OP exposure. Suratman et al demonstrated that farmworkers' knowledge and perceptions were two of the factors significantly related to the increase of OP exposure and OP poisoning both in developing and developed countries. ${ }^{11} \mathrm{In}$ Indonesia, Afriyanto demonstrated that occurrence of OP poisoning among chili sprayers was significantly influenced by knowledge and perceptions. ${ }^{12}$ On the other hand, Johnstone et al studied OP exposure in Australian agricultural workers and found that $>75 \%$ of farmworkers had a good knowledge about safe handling practices. ${ }^{13}$

OP exposure is a major occupational health concern particularly in Indonesia. ${ }^{3,4,12} \mathrm{~A}$ study by Kishi et $\mathrm{al}^{3}$ reported that $21 \%$ of OP sprayers had at least three or more symptoms, such as neurobehavioral, gastrointestinal, and respiratory symptoms related to OP exposure. Protective clothing, such as long-sleeved shirts, knee-high or long pants, coveralls, and personal protective equipment (PPE) such as chemical-resistant gloves, eyeglasses, head gear, and footgear are required during handling and applying OPs. They can reduce dermal contact and inhalation exposures. ${ }^{14}$ However, improvement of farmworkers' knowledge and perceptions is required for them to adopt these protective health behaviors such as the use of PPE. According to Rogers,${ }^{15}$ improvement in knowledge is the first stage to adopting new ideas, playing an important role in changing farmworkers' behavior, particularly in protecting themselves from OP exposure. A study by Arcury et a ${ }^{16}$ with 293 participant farmworkers in North Carolina, USA, demonstrated that knowledge of pesticide exposure had a significant relationship with perceived risk. In addition, safety knowledge was strongly related to perceived control. Another study by Zyoud et al ${ }^{17}$ with 381 participant farmworkers in Palestine showed that pesticide knowledge was significantly associated with work practices in handling pesticides in the field.

Low knowledge about adverse effects (AEs), perceived low severity of OP exposure, and perceived insusceptibility to OP toxicity were risk factors of inappropriate handling of OP compounds in Indonesia. ${ }^{12}$ In contrast, fruit and vegetable farmworkers in Australia generally have a good level of knowledge and perceptions of OP exposure. ${ }^{13}$ Educational interventions using a group communication and one-on-one approach, and the comparisons of knowledge and perceptions about OP exposure between farmworkers in Indonesia and migrant farmworkers in Australia have not been investigated previously. ${ }^{11}$

These reports suggest that improvements of knowledge and perceptions about OP exposure among Indonesian farmworkers and South Australian (SA) migrant farmworkers may be of benefit for reduction in OP exposure. The objective of the interventions in this study was to improve knowledge and perceptions about OP exposure among Indonesian and SA migrant farmworkers and to measure the effectiveness of provided interventions using two different methods, namely teaching in a class (PowerPoint slide and discussion) for Indonesian farmworkers and an individual approach (flipchart and discussion) for SA migrant farmworkers. In this paper, we present the effects of both interventions on OPs-related knowledge and perceptions. This was measured by conducting a quasi-experimental study. This paper represents the first intervention targeted particularly at reducing OP exposure among Indonesian and SA migrant farmworkers that has been assessed for behavioral changes and compared with Health Belief Model (HBM) theory.

\section{Materials and methods Study population}

This quasi-experimental study was conducted at two research sites, Dukuhlo Village in Brebes Regency, Central Java province, Indonesia, and in the Suburb of Virginia, Adelaide, South Australia, Australia. The choice of these distinct populations was due to a clear paucity of relevant research comparing knowledge and perceptions of OP exposure among farmworkers working and living in Indonesia as a developing country and in Australia as a developed country. ${ }^{11}$ Inclusion criteria were: 1) that they were male; and 2) had to be employed in farmwork within the past 3 months. These criteria were based on the following: 1) the majority of farmworkers in 2010-2011 in Australia $(139,500 \text { or } 72 \%)^{18}$ and in 2013 in Indonesia (24.36 million or $77 \%)^{19}$ were male; 2 ) engaging in farmwork within the past 3 months reflected recent likelihood of being exposed to OPs. In addition, complete recovery of plasma cholinesterase (PChE) as a biomarker of exposure to OPs and erythrocyte cholinesterase as a biomarker of toxicity is 50 days and 82 days, respectively. ${ }^{20}$

Thirty Indonesian farmworkers were given the educational intervention material through group presentations, whereas seven SA migrant farmworkers were given the intervention 
material during a one-on-one with the researcher. The ethnicity of SA migrant farmworkers was Vietnamese. Previous studies in developed countries have indicated that migrant farmworkers face a greater risk of illnesses and death due to pesticides exposure than the indigent farming community. ${ }^{21-24}$ This study was conducted from May to June, 2014 in Australia, and from July to August, 2014 in Indonesia for the baseline study (pre-intervention). Follow-up studies (post-intervention) were conducted from September to October, 2014 in Australia and from November to December, 2014 in Indonesia. The questions on personal characteristics were administered at baseline, before the intervention. The questions on knowledge and perceptions were administered at baseline and at 3 months after the intervention. Ethics approvals were obtained from the Southern Adelaide Clinical Human Research Ethics Committee (SACHREC) with approval number: 319.13, and from the Commission on Health Research Ethics, Faculty of Public Health, Diponegoro University, Semarang, Indonesia with approval number: 183/EC/FKM/2013. After participants signed the informed consent, they were then interviewed.

\section{Sample size estimation}

The required sample size was calculated based on previous studies ${ }^{25,26}$ using STATA IC/12.1 software (StataCorp LP, College Station, TX, USA). This program is used to determine the minimum number of participants needed for each research site, with power of the test $=90 \%$, level of significance $=0.05$, mean \pm standard deviation $(\mathrm{SD})=1.5 \pm 0.3 \mathrm{U} / \mathrm{mL}$ of $\mathrm{PChE}$ level (also known as butyrylcholinesterase) as a biomarker of exposure to OPs $\left(30 \%-74 \%\right.$ of normal), ${ }^{25}$ and mean \pm $\mathrm{SD}=2.0 \pm 0.4 \mathrm{U} / \mathrm{mL}$ of normal PChE level in a population. ${ }^{26}$ Sample size required for this study for each group was 20 . In Indonesia, 30 of 52 Indonesian farmworkers working and living at the Dukuhlo Village were randomly selected to accommodate missing data and possible dropout using a random number table generated by C-Survey v2.0 free software (Muhammad N Farid and Ralph R Frerichs, Los Angeles, USA). On the other hand, due to many difficulties in recruiting research participants in Australia, a snowball sampling method was used, which involved asking research participants to nominate another farmworker. This resulted in seven SA migrant farmworkers working and living in Virginia, South Australia, being included in this study.

\section{Research questionnaire instrument}

HBM theory was used to explain behavioral factors (knowledge and perceptions) as a basis for interventions. According to the HBM, there are four factors directly associated with individual behaviors. These factors consist of perceived susceptibility, perceived severity, perceived benefits, and perceived barriers which are modified by other variables such as culture, education level, age, sex, ethnicity, past experience, knowledge, and cues to action. ${ }^{27,28}$ Perceived susceptibility is a powerful perception, which leads farmworkers to adopt healthier behaviors. Farmworkers must perceive their susceptibility to risk before they will take action.

The questionnaire was written in English and was translated into Indonesian language. The questionnaire data collection both in Indonesia and in Australia was conducted by the first author in face-to-face interviews (interviewer-administered questionnaire). The author clarified and explained misunderstood questions. In Indonesia, the first author, of native Indonesian ancestry, used Indonesian language to ask all questions. In Australia, the first author used English to collect data from SA migrant farmworkers. We did not assess the level of their English proficiency before we asked questions. However, more than half of the research participants (57\%) could speak English well. When we interviewed research participants who could not speak English fluently, we asked for help from someone, such as a family member who was fluent in English to translate, in order to avoid misunderstanding in answering questions. Original questions were developed for knowledge about AEs of OPs (Figure S1), knowledge about self-protection from OP exposure (Figure S2), and perceptions about OP exposure (perceived susceptibility, perceived severity, perceived benefits, perceived barriers, and cues to action) (Figure S3). The questionnaire consisted of: 1) personal characteristics age, years working as a farmworker, and level of education; 2) knowledge about AEs of OPs as assessed by 12 close-ended questions; 3) knowledge about self-protection from OP exposure as assessed by ten close-ended questions; 4) perceptions about OP exposure as assessed by 20 close-ended questions. These 20 questions about perceptions encompassed perceived susceptibility (six questions), perceived severity (four questions), perceived benefits (two questions), perceived barriers (four questions), and cues to action (four questions).

For true/false questions, if the question was answered correctly, the score was 2 . If the respondents ticked "don't know", the score for that question was 1 , and if they answered incorrectly, the score was 0 . Total possible score of knowledge about AEs of OPs ranged from 0 to 24 and total possible score of knowledge about self-protection from OP exposure ranged from 0 to 20 .

The questions of perceptions had five response options, namely "strongly disagree", "disagree", "neutral”, "agree”, and 
"strongly agree" using Likert scale ranging from 5 for positive perception answer to 1 for negative perception answer.

Positive statement questions contained a statement which may lead farmworkers to practice healthy behavior in reducing OP exposure (eg, C11 "Use of PPE will protect the body from AEs of pesticide exposure", Figure S3). On the other hand, negative statement questions were aimed at a belief, which may inhibit farmworkers to practice healthy behavior in reducing OP exposure (eg, C9 "The effect of pesticide on the body is easily cured", Figure S3). Total possible perception scores ranged from 6 to 30 for perceived susceptibility, 4 to 20 for perceived severity, 2 to 10 for perceived benefits, 4 to 20 for perceived barriers, and 4 to 20 for cues to action. The knowledge questions and perceptions questions are presented in the Figures S1-S3.

The questionnaire was validated with pilot testing for clarity and reliability on 12 nonoccupationally exposed persons, by the first author. Pearson's product moment correlation $(r)$ and Cronbach's alpha tests were calculated to assess construct validity and internal consistency, respectively. Construct validity measured by the correlation between a score from an individual question and a total score of all questions showed the $r$ for individual knowledge and perceptions questions was $>0.50(P<0.05)$. Meanwhile, Cronbach's alpha demonstrated good reliability, with Cronbach's alpha for knowledge about AEs of OPs, knowledge about self-protection from OP exposure, and perceptions about OP exposure $0.72,0.71$, and 0.73 , respectively (where 0 is unreliable and 1 is very reliable). Tests of validity and reliability for a translated questionnaire (Indonesian language) were not conducted. The first author translated the questionnaire ensuring the meaning of each translated question written in Indonesian was the same as in the English questionnaire.

The intervention program in each group lasted for 1 hour based primarily on the HBM theory to improve knowledge and perceptions of OP exposure. The provided information covered the following: 1) definition of pesticides; 2) groups of pesticides; 3) pathways of OP exposure at workplace and at home; 4) adverse health effects of OPs; 5) signs and symptoms of acute and chronic effects due to OP exposure; 6) self-protection from OP exposure at workplace; 7) selfprotection from OP exposure at home; 8) PPE; and 9) first aid when exposed to OP exposure.

The interventions used two modes of educational delivery: a PowerPoint presentation was used for Indonesian farmworkers and a flipchart was used for SA migrant farmworkers with the same content. Different methods of educational interventions were used to accommodate the local conditions. In Indonesia, the intervention using PowerPoint presentation was suitable for the Indonesian community because the research participants lived in the same village. Thirty Indonesian farmworkers were divided into two groups (the first group consisted of 20 farmworkers and the second group consisted of ten farmworkers). This was to ensure the audiences were not too large (no more than 20 persons per group intervention). The participants gathered at a village hall on separate days for each group. The information was conveyed by the first author, using Indonesian language and was followed by a discussion (Figure 1). Meanwhile, SA migrant farmworkers were provided intervention in English language using a flipchart followed by a discussion (Figure 2). For SA migrant farmworkers, the intervention was delivered individually, which was a suitable method for farmworkers who did not live in the same place and the researcher needed to present the material at their workplace (the farm) by prior appointment to accommodate the participants' work schedules.

\section{Data analysis}

Descriptive statistics were used to describe mean, SDs, frequencies, percentages for personal characteristics, and for knowledge and perceptions scores. Continuous data were tested for normal distribution using the Shapiro-Wilk test. ${ }^{29,30}$ Baseline differences in knowledge and perceptions between Indonesian and SA migrant farmworkers were tested by either unpaired $t$-test or Mann-Whitney $U$ test.

At follow-up (post-intervention), the magnitude of the intervention effect was the difference between Indonesian and SA migrant farmworkers in the change of mean score from preintervention to post-intervention. The outcome measure was the difference in the magnitude of intervention effect between before and after intervention and between the study groups. It was assessed as the change in the mean scores of knowledge and perceptions about OP exposure from the baseline data (pre-intervention) to follow-up (post-intervention).

The formula to calculate intervention effects was as follows: ${ }^{31}$

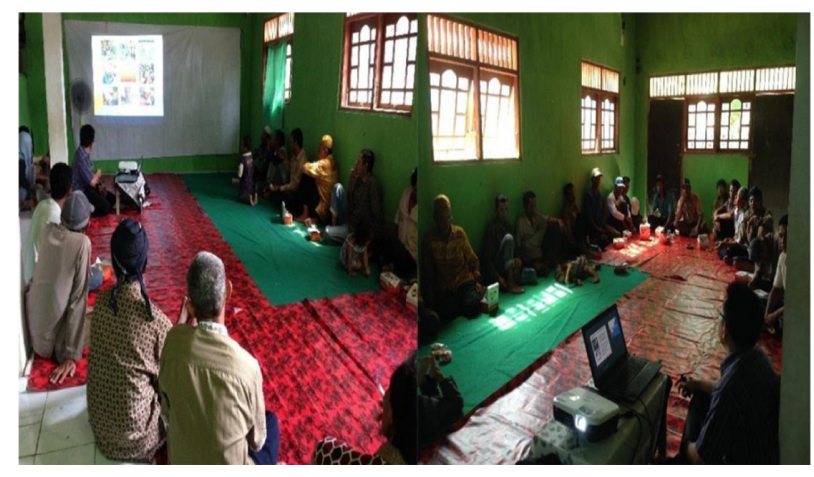

Figure I Providing intervention at Dukuhlo Village, Brebes Regency, Indonesia. 


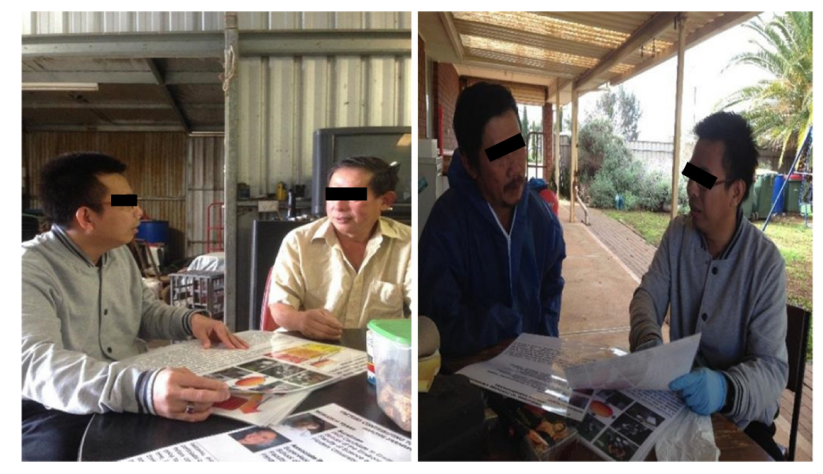

Figure 2 Providing intervention at Suburb of Virginia, North Adelaide, South Australia, Australia.

Intervention effects $=(\text { follow-up }- \text { baseline })_{\text {intervention }}-$ (follow-up - baseline) control $_{\text {}}$

Linear mixed models were constructed to test the statistical significance of intervention effects on knowledge and perception scores measured 3 months after the intervention (follow-up time). Unadjusted fixed-effects models were used to assess the main effects of intervention and follow-up time, and an intervention-time interaction term for follow-up time. The first model consisted of time as the repeated measure, the study participant as the individual subject, and an unstructured covariance type. Level of statistical significance ( $P$-value) was set at $\alpha=0.05$.

In a second model, used to control confounding variables, interventions effects were adjusted for level of education and years working as a farmworker. These significantly differed between Indonesian and SA migrant farmworkers $(P<0.05)$, reported in pre-intervention. These two variables significantly influenced knowledge and perceptions of farmworkers. ${ }^{31,32}$ Intervention effects are therefore presented as absolute magnitudes and percentages of baseline mean scores. Statistical analyses were performed using the statistical package SPSS version 17 (SPSS Inc., Chicago, IL, USA).

\section{Results}

Variables of personal characteristics are summarized and compared between Indonesian and SA migrant farmworkers in Table 1. Years working as a farmworker was statistically significantly higher in Indonesian farmworkers than SA migrant farmworkers. Meanwhile, the level of education was statistically significantly higher in SA migrant farmworkers than in Indonesian farmworkers. Thus, intervention effects on knowledge and perceptions were adjusted for these characteristics. Age was not significantly different between
Table I Baseline characteristics compared between Indonesian and SA migrant farmworkers

\begin{tabular}{|c|c|c|c|c|c|}
\hline \multirow[t]{2}{*}{ Characteristics } & \multicolumn{2}{|c|}{$\begin{array}{l}\text { Indonesian } \\
\text { farmworkers } \\
(n=30)\end{array}$} & \multicolumn{2}{|c|}{$\begin{array}{l}\text { SA migrant } \\
\text { farmworkers } \\
(n=7)\end{array}$} & \multirow[t]{2}{*}{$P$-value* } \\
\hline & Mean & SD & Mean & SD & \\
\hline \multicolumn{6}{|l|}{ Continuous variables } \\
\hline Age (years) & 54.1 & 7.2 & 50.9 & 13.0 & 0.364 \\
\hline $\begin{array}{l}\text { Years working as a } \\
\text { farmworker }\end{array}$ & 31.3 & 9.1 & 16.7 & 11.6 & 0.001 \\
\hline Categorical variable & $\mathbf{n}$ & $\%$ & $\mathbf{n}$ & $\%$ & $P$-value** \\
\hline Level of education & & & & & 0.000 \\
\hline None & 4 & 13.3 & 0 & 0.0 & \\
\hline Elementary school & 20 & 66.8 & 0 & 0.0 & \\
\hline Junior high school & 4 & 13.3 & 0 & 0.0 & \\
\hline Senior high school & I & 3.3 & 2 & 28.6 & \\
\hline Diploma (DI/D2/D3) & I & 3.3 & 3 & 42.8 & \\
\hline University & 0 & 0.0 & 2 & 28.6 & \\
\hline
\end{tabular}

Notes: *By unpaired $t$-test; **by chi-square test.

Abbreviations: SA, South Australian; SD, standard deviation.

the two study groups $(P>0.05)$, so no adjustment was made for its variable.

Unadjusted intervention effects at follow-up are shown in Table 2. The intervention was related to substantial and statistically significant improvement in scores of knowledge about AEs of OPs, knowledge about self-protection from OP exposure, perceived susceptibility, and perceived barriers at

Table 2 Absolute magnitudes of unadjusted intervention effects on knowledge score and perceptions score, and intervention effects as percentages of baseline and follow-up scores

\begin{tabular}{|c|c|c|c|c|}
\hline \multirow[t]{3}{*}{ Variables } & \multirow{3}{*}{$\begin{array}{l}\text { Overall } \\
\text { mean at } \\
\text { baseline }\end{array}$} & \multirow{2}{*}{\multicolumn{3}{|c|}{$\begin{array}{l}\begin{array}{l}\text { Intervention effects } \\
\text { (unadjusted) }\end{array} \\
\text { Follow-up }\end{array}$}} \\
\hline & & & & \\
\hline & & $\begin{array}{l}\text { Absolute } \\
\text { magnitude } \\
(95 \% \mathrm{Cl}) \\
\end{array}$ & $P$-value & $\begin{array}{l}\text { As \% of } \\
\text { baseline } \\
\text { mean }\end{array}$ \\
\hline $\begin{array}{l}\text { Score of knowledge } \\
\text { about adverse effects } \\
\text { of OPs }\end{array}$ & 13.7 & $3.0(1.6-4.4)$ & $<0.001$ & 21.9 \\
\hline $\begin{array}{l}\text { Score of knowledge } \\
\text { about self-protection } \\
\text { from OP exposure }\end{array}$ & 14.8 & $1.3(0.1-2.5)$ & 0.040 & 8.8 \\
\hline $\begin{array}{l}\text { Score of perceived } \\
\text { susceptibility }\end{array}$ & 20.9 & $1.7(0.5-2.9)$ & 0.007 & 8.1 \\
\hline $\begin{array}{l}\text { Score of perceived } \\
\text { severity }\end{array}$ & 9.9 & $0.5(-0.1-1.1)$ & 0.115 & 5.1 \\
\hline $\begin{array}{l}\text { Score of perceived } \\
\text { benefits }\end{array}$ & 8.4 & $0.5(-0.4-1.3)$ & 0.271 & 5.9 \\
\hline $\begin{array}{l}\text { Score of perceived } \\
\text { barriers }\end{array}$ & 9.9 & $0.7(0.2-1.3)$ & 0.012 & 7.1 \\
\hline $\begin{array}{l}\text { Score of cues to } \\
\text { action }\end{array}$ & 13.9 & $0.2(-0.3-0.8)$ & 0.425 & 1.4 \\
\hline
\end{tabular}

Abbreviations: $\mathrm{Cl}$, confidence interval; OPs, organophosphate pesticide; OP, organophosphate. 
follow-up time $(P \leq 0.05)$. Meanwhile, scores of perceived severity, perceived benefits, and cues to action did not statistically improve at follow-up time $(P>0.05)$. For example, from baseline to follow-up, scores of knowledge about AEs of OPs increased by 3 points more in Indonesian farmworkers than SA migrant farmworkers. This represented an interventionrelated improvement of $21.9 \%$ of the baseline mean score of knowledge about AEs of OPs.

Adjusted intervention effects are presented in Table 3. The results of adjusted intervention effects, like unadjusted ones, were consistently beneficial and statistically significant $(P<0.05)$ for the variables of knowledge about AEs of OPs, knowledge about self-protection from OP exposure, perceived susceptibility, and perceived barriers $(P<0.05)$. The variables of perceived severity and perceived benefits statistically were significant after being adjusted for level of education and years working as a farmworker. On the other hand, variable cues to action was not significant in both statistical analyses.

A comparison of Tables 2 and 3 indicates that adjustment was significant in increasing the differences in modeled benefits of the intervention presented by both absolute magnitude and a percentage of the baseline mean scores.

Adjusted mean scores of knowledge about AEs of OPs and knowledge about self-protection from OP exposure in Indonesian farmworkers and SA migrant farmworkers,

Table 3 Absolute magnitudes of adjusted intervention effects on knowledge score and perceptions score, and intervention effects as percentages of baseline and follow-up scores

\begin{tabular}{|c|c|c|c|c|}
\hline \multirow[t]{3}{*}{ Variables } & \multirow{3}{*}{$\begin{array}{l}\text { Overall } \\
\text { mean at } \\
\text { baseline }\end{array}$} & \multicolumn{3}{|c|}{ Intervention effects (adjusted) } \\
\hline & & \multicolumn{3}{|l|}{ Follow-up } \\
\hline & & $\begin{array}{l}\text { Absolute } \\
\text { magnitude } \\
(95 \% \mathrm{Cl})\end{array}$ & $P$-value & $\begin{array}{l}\text { As } \% \text { of } \\
\text { baseline } \\
\text { mean }\end{array}$ \\
\hline $\begin{array}{l}\text { Score of knowledge } \\
\text { about adverse effects } \\
\text { of OPs }\end{array}$ & 13.7 & $3.4(2.3-4.5)$ & $<0.001$ & 24.8 \\
\hline $\begin{array}{l}\text { Score of knowledge } \\
\text { about self-protection } \\
\text { from OP exposure }\end{array}$ & 14.8 & $1.9(0.9-2.9)$ & $<0.001$ & 12.8 \\
\hline $\begin{array}{l}\text { Score of perceived } \\
\text { susceptibility }\end{array}$ & 20.9 & $2.8(1.7-3.8)$ & $<0.001$ & 13.4 \\
\hline $\begin{array}{l}\text { Score of perceived } \\
\text { severity }\end{array}$ & 9.9 & $0.8(0.3-1.3)$ & 0.002 & 8.1 \\
\hline $\begin{array}{l}\text { Score of perceived } \\
\text { benefits }\end{array}$ & 8.4 & $0.7(0.1-1.4)$ & 0.027 & 8.3 \\
\hline $\begin{array}{l}\text { Score of perceived } \\
\text { barriers }\end{array}$ & 9.9 & $1.2(0.7-1.6)$ & $<0.001$ & 12.1 \\
\hline $\begin{array}{l}\text { Score of cues to } \\
\text { action }\end{array}$ & 13.9 & $0.4(-0.1-0.8)$ & 0.102 & 2.9 \\
\hline
\end{tabular}

Abbreviations: $\mathrm{Cl}$, confidence interval; OPs, organophosphate pesticide; OP, organophosphate. at two measurement times, are shown in Figures 3 and 4, respectively.

Adjusted mean scores of perceptions about OP exposure in Indonesian farmworkers and SA migrant farmworkers, at two measurement times are shown in Figures 6-9 (perceived susceptibility [Figure 5], perceived severity [Figure 6], perceived benefits [Figure 7], perceived barriers [Figure 8], and cues to action [Figure 9]). These figures illustrate that the increases in both scores from baseline to follow-up were greater in Indonesian farmworkers. This demonstrates the beneficial effect of the intervention on both scores by using the method of presenting PowerPoint slides followed by discussion.

\section{Discussion}

This study found that locally tailored educational interventions improved the farmworkers' knowledge and perceptions of OP exposure after adjusting for level of education and years working as a farmworker (Table 3). The results of this study support those reported by Boonyakawee et $\mathrm{al}^{31}$ in Thailand, which reported that farmworkers improved their knowledge after being provided training in insecticide-related knowledge. These results indicated that the objectives of the interventions were attained, except for cues to action. Knowledge about AEs of OPs and self-protection from OP exposure support the HBM. In the HBM theory, knowledge is one of the modifying factors that has a direct relationship with individual beliefs (perceived susceptibility, perceived severity, perceived benefits, and perceived barriers) and an indirect relationship with individual behaviors. ${ }^{27}$ Knowledge of health risks and benefits of different health practices creates the precondition to practice health behavior. ${ }^{33}$

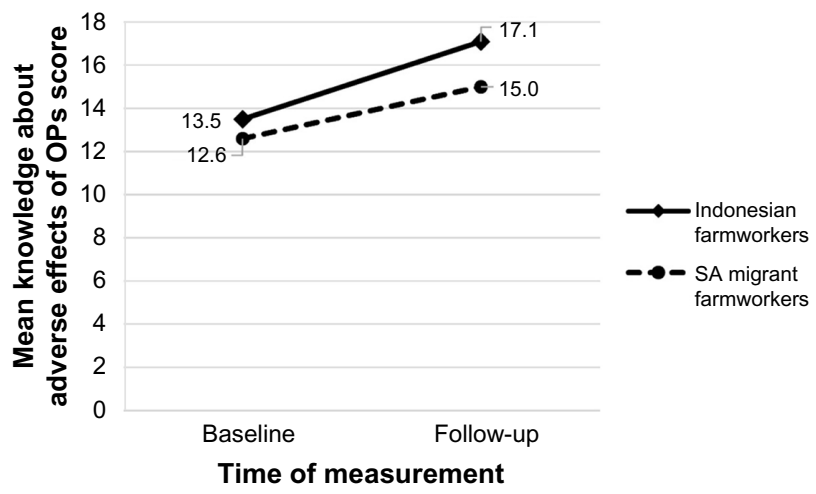

Figure 3 Adjusted mean score of knowledge about adverse effects of OPs in Indonesian farmworkers and SA migrant farmworkers at baseline and follow-up. Notes: Scores were adjusted for level of education and years working as a farmworker. The follow up is at 3 months after the intervention. Abbreviations: OPs, organophosphate pesticide; SA, South Australian. 


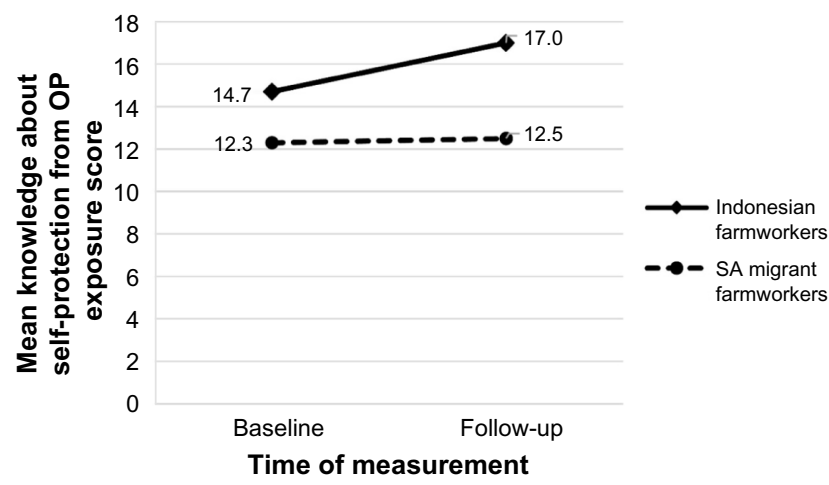

Figure 4 Adjusted mean score of knowledge about self-protection from OP exposure in Indonesian farmworkers and SA migrant farmworkers at baseline and follow-up. The follow up is at 3 months after the intervention.

Notes: Scores were adjusted for level of education and years working as a farmworker.

Abbreviations: OP, organophosphate; SA, South Australian.

The interventions improved farmworkers' knowledge of OP toxicity, pathways of OP exposure at workplace and at home, signs and symptoms of acute and chronic effects due to OP exposure, self-protection from OP exposure at workplace and at home, PPE, and the first aid when exposed to OPs. In addition, the interventions improved the workers' perceptions about $\mathrm{OP}$ exposure, including perceived susceptibility, perceived severity, perceived benefits, and perceived barriers. Two of four major constructs of perception are perceived susceptibility and perceived severity. ${ }^{27,28}$ Perceived susceptibility refers to person's subjective perceptions regarding the risk of health conditions. In the case of a medical illness, these dimensions include acceptance of a diagnosis, personalized forecast for the re-susceptibility, and susceptibility toward a disease in general..$^{27,34,35}$ Feeling susceptible to a condition which leads to a serious disease can encourage farmworkers to change their behavior. ${ }^{27,28}$ It depends on one's belief of the effectiveness of the various measures available to reduce the

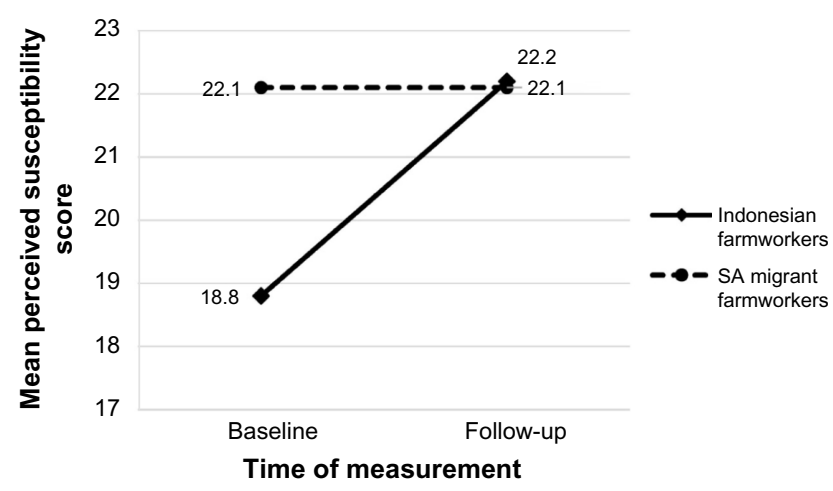

Figure $\mathbf{5}$ Adjusted mean score of perceived susceptibility in Indonesian farmworkers and SA migrant farmworkers at baseline and follow-up.

Notes: Scores were adjusted for level of education and years working as a farmworker. The follow up is at 3 months after the intervention.

Abbreviation: SA, South Australian.

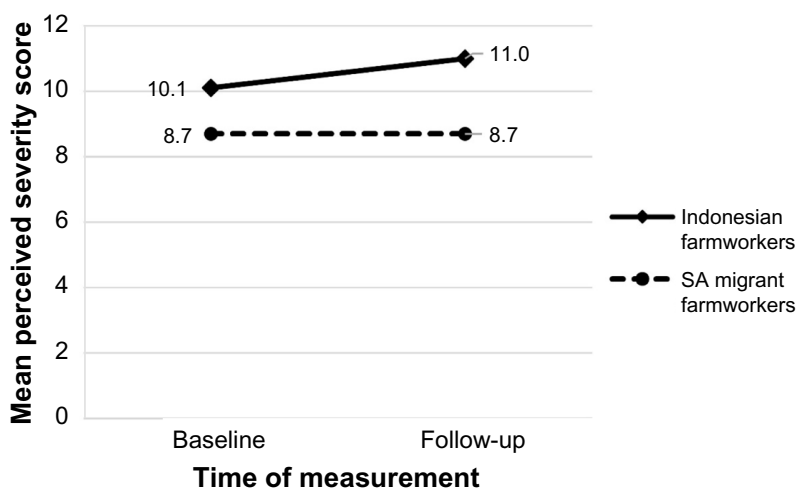

Figure 6 Adjusted mean score of perceived severity in Indonesian farmworkers and SA migrant farmworkers at baseline and follow-up.

Notes: Scores were adjusted for level of education and years working as a farmworker. The follow up is at 3 months after the intervention.

Abbreviation: SA, South Australian.

threat of disease, or the perceived benefits in making health efforts. Meanwhile, perceived severity refers to feelings about the seriousness of the disease, including the evaluation of the clinical and medical consequences (eg, death, disability, and pain) and social consequences that may occur (such as the effects on employment, family life, and social relationships)..$^{27,34,35}$ Perceived barriers appear due to heightened view of potential negative aspects of health-related behavior change. Factors, such as uncertainty, side effects, and questions about suitability, anxiety, and stress may act as a barrier to changing behavior. ${ }^{27,34,35}$ In addition, according to the HBM theory, behavior is also influenced by cues to action. Cues to action are events, things, or people that/who encourage or trigger people to change their behavior by using appropriate reminder systems, promoting awareness, or providing information..$^{27,34,35}$

Indonesian farmworkers had significant improvement for almost all measured variables (knowledge and perceptions),

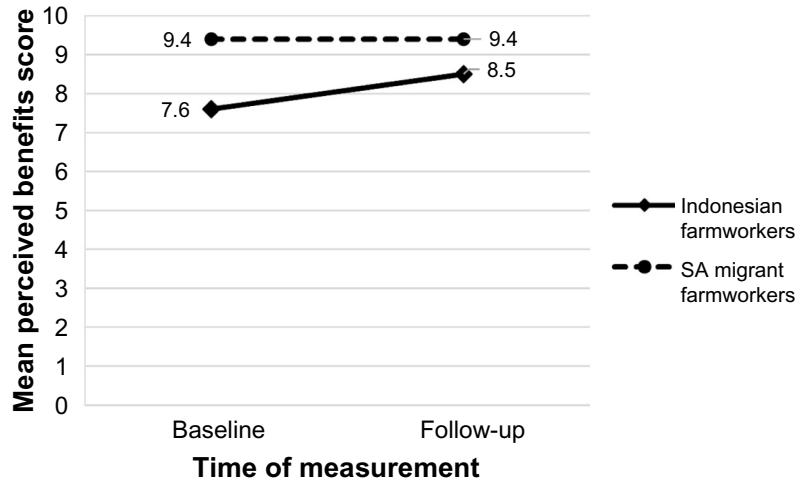

Figure 7 Adjusted mean score of perceived benefits in Indonesian farmworkers and SA migrant farmworkers at baseline and follow-up.

Notes: Scores were adjusted for level of education and years working as a farmworker. The follow up is at 3 months after the intervention. Abbreviation: SA, South Australian. 


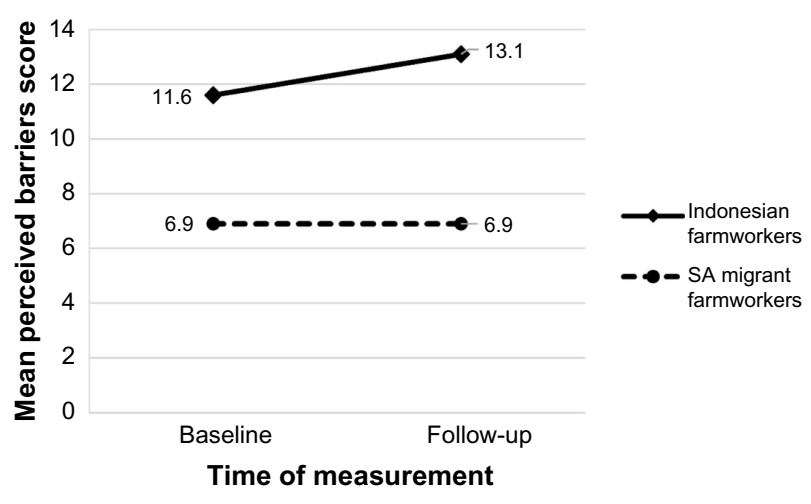

Figure 8 Adjusted mean score of perceived barriers in Indonesian farmworkers and SA migrant farmworkers at baseline and follow-up.

Notes: Scores were adjusted for level of education and years working as a farmworker. The follow up is at 3 months after the intervention.

Abbreviation: SA, South Australian.

except for cues to action. On the other hand, SA migrant farmworkers had significant improvement in mean score of knowledge about AEs of OPs whereas mean score of knowledge about self-protection from OP exposure had insignificant improvement and mean scores of all aspects of perceptions remained constant.

The intervention of health education provided to farmworkers in both groups was viewed as an innovation. ${ }^{36}$ Different methods of educational interventions between groups might influence effectiveness of provided interventions. ${ }^{37}$ Group intervention was used for Indonesian farmworkers whereas individual intervention was used for SA migrant farmworkers. Geographical area was the main reason for using different methods of educational interventions. In Indonesia, the research participants lived in the same village and were easily gathered together. In South Australia, the research participants did not live in the same area and only

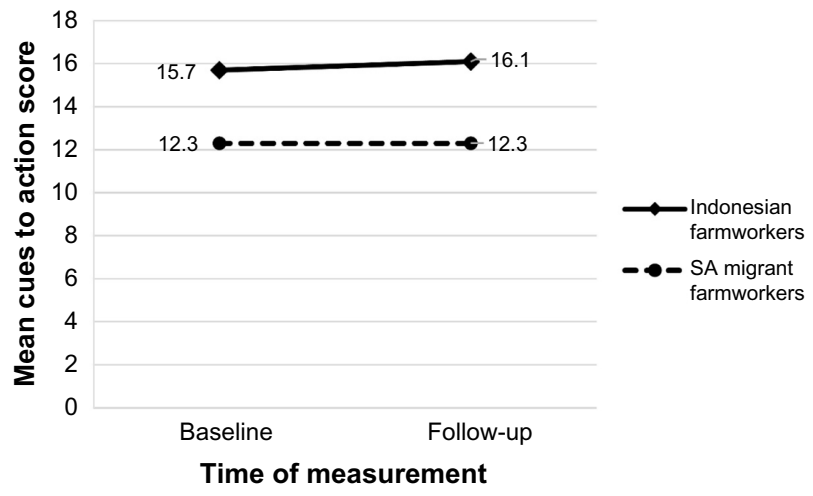

Figure 9 Adjusted mean score of cues to action in Indonesian farmworkers and SA migrant farmworkers at baseline and follow-up.

Notes: Scores were adjusted for level of education and years working as a farmworker. The follow up is at 3 months after the intervention.

Abbreviation: SA, South Australian. could be visited in their farm areas by making an appointment first.

During the intervention, the research participants in Indonesia were active and participants in all processes of the intervention, including listening, discussing, interacting, or explaining their experiences in using OPs. On the other hand, in South Australia, a one-on-one approach using a flipchart was the method used to convey information. All research participants in South Australia were Vietnamese, and were prone to be passive participants. This might be due to limited English language proficiency and therefore the participants might be hesitant in expressing their opinions in English language. The messages are much more effectively understood, when the target groups have an opportunity to express their opinions and interact. ${ }^{37}$

\section{Methodological considerations}

The intervention in this study was specifically targeted to reduce OP exposure. The sample was limited to one village of one regency in Indonesia (30 Indonesian farmworkers) and one region of one state in Australia (seven SA migrant farmworkers) due to difficulties in recruiting research participants in Australia. The intervention program lasted only for 1 hour, so possibly greater improvement post-intervention would have been observed had the educational intervention been delivered over a longer timeframe. In addition, this study only adjusted two factors, namely level of education and years of working as a farmworker, as covariates. We did not measure other external factors such as government awareness programs, information obtained from other sources such as the media, etc, which might influence the scores of knowledge and perceptions in the follow-up measurement. Therefore, information bias might occur. Notwithstanding, the improvements resulted by the intervention in this study provide starting points to change the behavior of farmworkers, particularly to reduce OP exposure both at the workplace and at home.

\section{Conclusion}

Indonesian farmworkers had significant improvements in almost all aspects of knowledge and perceptions about OP exposure in the follow-up measurement after providing the interventions. In contrast, SA migrant farmworkers had insignificant improvements in all measured variables, except for knowledge about AEs of OPs. This might be due to the different methods of the interventions provided to both groups. The use of group communication was more effective to improve farmworkers' knowledge and perceptions than individual approach. 
SA migrant farmworkers require a specific method of educational intervention to improve their knowledge and perceptions of OP exposure. Following ChemCert courses to obtain chemical accreditations conducted by the ChemCert Training Group ${ }^{38}$ before working in agricultural sector is a suitable option to improve knowledge and the skills of SA migrant farmworkers in performing duties safely.

Further research needs to be conducted using long-term intervention methods, particularly for Indonesian farmworkers, to assess the effectiveness of interventions associated with changes of health behavior outcomes.

\section{Acknowledgments}

The authors are grateful to the Directorate General of Higher Education (DIKTI) of the Republic of Indonesia for providing the scholarships in the PhD program at the School of the Environment, Flinders University, South Australia, Australia. Special thanks to the farmworkers in Indonesia and South Australia for their kind support throughout the study.

\section{Disclosure}

The authors report no conflicts of interest in this work.

\section{References}

1. Jeyaratnam J. Acute pesticide poisoning: a major global health problem. World Health Stat Q. 1990;43(3):139-144.

2. Zhang X, Zhao W, Jing R, et al. Work-related pesticide poisoning among farmers in two villages of Southern China: a cross-sectional survey. BMC Public Health. 2011;11:429.

3. Kishi M, Hirschhorn N, Djajadisastra M, Satterlee LN, Strowman S, Dilts R. Relationship of pesticide spraying to signs and symptoms in Indonesian farmers. Scand J Work Environ Health. 1995;21(2): 124-133.

4. Rustia HN, Wispriyono B, Susanna D, Luthfiah FN. Organophosphate pesticide exposure effects toward inhibition of blood cholinesterase activity among vegetable farmers. Makara, Kesehatan. 2010;14(2): 95-101.

5. Dasgupta S, Meisner C, Wheeler D, Xuyen K, Thi Lam N. Pesticide poisoning of farm workers-implications of blood test results from Vietnam. Int J Hyg Environ Health. 2007;210(2):121-132.

6. Faria NM, Fassa AG, Meucci RD, Fiori NS, Miranda VI. Occupational exposure to pesticides, nicotine and minor psychiatric disorders among tobacco farmers in southern Brazil. Neurotoxicology. 2014;45: 347-354

7. Das R, Vergara X, Sutton P, Gabbard S, Nakamoto J. The San Luis Obispo County Farmworker Survey. Implementation of Worker Safety Regulations: A Survey of Farmworker Perspectives and Health Issues. California: California Department of Health Services, 2002. Available from: https://www.cdph.ca.gov/programs/ohsep/Documents/slosurvey. pdf. Accessed October 13, 2012.

8. Beseler CL, Stallones L. A cohort study of pesticide poisoning and depression in Colorado farm residents. Ann Epidemiol. 2008;18(10): $768-774$.

9. Lee SJ, Mehler L, Beckman J, et al. Acute pesticide illnesses associated with off-target pesticide drift from agricultural applications: 11 States, 1998-2006. Environ Health Perspect. 2011;119(8):1162-1169.

10. He F. Workshop on organophosphate (OP) poisoning: organophosphate poisoning in China. Hum Exp Toxicol. 1996;15(1):72.
11. Suratman, Edwards JW, Babina K. Organophosphate pesticides exposure among farmworkers: pathways and risk of adverse health effects. Rev Environ Health. 2015;30(1):65-79.

12. Afriyanto. Study of pesticide poisoning among chili sprayers at Candi Village, Bandungan Sub District, Semarang Regency [Thesis]. Semarang: Diponegoro University, Semarang, Indonesia; 2008.

13. Johnstone K, Capra M, Newman B. Organophosphate pesticide exposure in agricultural workers: Human exposure and risk assessment. Barton, Australian Capital Territory: Rural Industries Research and Development Corporation, Australian Government, 2007. Contract No: RIRDC Publication No 07/154 and RIRDC Project No QUT-5A. Available from: https://rirdc.infoservices.com. au/downloads/07-154.pdf. Accessed September 29, 2012.

14. Fenske RA, Edgar W, Day J. Assessment of exposure for pesticide handlers in agricultural, residential and institutional environments. In: Franklin CA, Worgan JP, editors. Occupational and Residential Exposure Assessment for Pesticides. John Wiley \& Sons, Ltd; 2005: $13-43$.

15. Rogers EM. Diffusion of Innovations. 3rd ed. London: The Free Press; 1983.

16. Arcury TA, Quandt SA, Russell GB. Pesticide safety among farmworkers: Perceived risk and perceived control as factors reflecting environmental justice. Environ Health Perspect. 2002;110(Suppl 2): 233-240.

17. Zyoud SH, Sawalha AF, Sweileh WM, et al. Knowledge and practices of pesticide use among farm workers in the West Bank, Palestine: safety implications. Environ Health Prev Med. 2010;15(4):252-261.

18. Australian Bureau of Statistics. 1301.0 - Year Book Australia, 2012. Canberra, Australia; 2012. Available from: http://www.abs.gov.au/ ausstats/abs@.nsf/Lookup/1301.0Main+Features3032012. Accessed November 27, 2012.

19. Indonesian Bureau of Statistics. Laporan hasil sensus pertanian 2013 [The results of agricultural census in 2013]. Jakarta, Indonesia; 2013:16. Indonesian. Available from: http://st2013.bps.go.id/st2013esya/booklet/ at3300.pdf. Accessed November 25, 2015.

20. Mason HJ. The recovery of plasma cholinesterase and erythrocyte acetylcholinesterase activity in workers after over-exposure to dichlorvos. Occup Med (Lond). 2000;50(5):343-347.

21. Levine MJ. Pesticides: A Toxic Time Bomb in Our Midst. Westport, Connecticut, London: Praeger; 2007. Available from: https://www. google.co.nz/url? sa=t\&rct=j\&q=\&esrc=s\&source=web\&cd=1\&cad $=$ rja\&uact=8\&ved=0ahUKEwig45ry4MjJAhVIrJQKHY9bAf0QF ggaMAA\&url=http $\% 3 \mathrm{~A} \% 2 \mathrm{~F} \% 2 \mathrm{~F}$ citeseerx.ist.psu.edu $\% 2 \mathrm{Fviewdo-}$ c\%2Fdownload\%3Fdoi\%3D10.1.1.452.3526\%26rep\%3Drep 1\%2 6type\%3Dpdf\&usg=AFQjCNG5SXFutjvkqXyJKyQ7FU1fsIzmp w\&sig2=lw2k-ATEEUpAZWB5mK7yxQ. Accessed October 26, 2011.

22. Reidy TJ, Bowler RM, Rauch SS, Pedroza GI. Pesticide exposure and neuropsychological impairment in migrant farm workers. Arch Clin Neuropsychol. 1992;7(1):85-95.

23. Arcury TA, Quandt SA. Pesticides at work and at home exposure of migrant farmworkers. Lancet. 2003;362(9400):2021.

24. Ciesielski S, Loomis DP, Mims SR, Auer A. Pesticide exposures, cholinesterase depression, and symptoms among North Carolina migrant farmworker. Am J Public Health. 1994;84(3):446-451.

25. Miranda-Contreras L, Gómez-Pérez R, Rojas G, et al. Occupational exposure to organophosphate and carbamate pesticides affects sperm chromatin integrity and reproductive hormone levels among Venezuelan farm workers. J Occup Health. 2013;55(3):195-203.

26. EQM Research I. Test-Mate ChE Cholinesterase Test System (Model 400), Instruction Manual. Cincinnati, Ohio, USA; 2011. Available from: http://www.eqmresearch.com/Manual-E.pdf. Accessed September 24, 2012.

27. Champion VL, Skinner CS. The Health Belief Model. In: Glanz K, Rimer BK, Viswanath K, editors. Health Behavior and Health Education Theory, Research, and Practice, 4th edition. San Francisco: Jossey-Bass A Wiley Imprint; 2008:45-65. 
28. Stretcher VJ, Champion VL, Rosenstock IM. The health belief model and health behavior. In: Gochman DS, editor. Handbook of health behavior research. New York: Plenum Press; 1997:71-91.

29. Elliot AC, Woodward WA. Statistical Analysis Quick Reference Guidebook with Spss Examples. 1st ed. London: Sage Publications; 2007.

30. Razali NM, Wah YB. Power comparisons of Shapiro-Wilk, Kolmogorov-Smirnov, Lilliefors and Anderson-Darling tests. JOSMA. 2011;2(1):21-33.

31. Boonyakawee P, Taneepanichskul S, Chapman RS. Effects of an intervention to reduce insecticide exposure on insecticide-related knowledge and attitude: a quasi-experimental study in Shogun orange farmers in Krabi Province, Thailand. Risk Manag Health Policy. 2013;6:33-41.

32. Parveen $\mathrm{S}$, Nakagoshi N. An analysis of pesticide use for rice pest management in Bangladesh. J Int Dev Coop. 2001;8(7):107-126.

33. Bandura A. Health promotion by social cognitive means. Health Education and Behavior. 2004;31(2):143-164.

34. Brandt EN, Baird MA, Berkman LF, et al. Health and Behavior: The Interplay of Biological, Behavioral, and Societal Influences. Washington DC: National Academy Press; 2001.
35. Clark NM, Houle CR. Theoretical models and strategies for improving disease management by patients. In: Shumaker SA, Ockene JK, Riekert KA, editors. The Handbook of Health Behavior Change, Third Edition. New York: Springer Publishing Company; 2009:19-38.

36. Health education: Theoretical Concepts, Effective Strategies and Core Competencies, A Foundation Document to Guide Capacity Development of Health Educators. WHO Regional Office for the Eastern Mediterranean; 2012. Available from: http://www.emro.who.int/dsaf/ EMRPUB_2012_EN_1362.pdf. Accessed April 14, 2015.

37. ILEP. ILEP Technical Bulletin 13: planning health education interventions. London, UK: ILEP; 1998:1-3.

38. Radcliffe, JC. Pesticide use in Australia: a review undertaken by the Australian Academy of Technological Sciences and Engineering. Australia: Australian Academy of Technological Sciences and Engineering; 2002. Available from: www.atse.org.au. Accessed October $20,2012$. 


\section{Supplementary materials}

\begin{tabular}{|c|c|c|c|c|}
\hline Q \# & Statements & $\mathbf{T}$ & $\mathbf{F}$ & DK \\
\hline A1 & OP is not one of the insecticide types & $\square$ & $\sqrt{ }$ & \\
\hline $\mathrm{A} 2$ & Fungicides are more toxic than insecticides & $\square$ & $\sqrt{ }$ & \\
\hline A3 & Insecticides are not harmful for human health & \begin{tabular}{|l|l} 
\\
\end{tabular} & $\sqrt{ }$ & \\
\hline A4 & $\begin{array}{l}\text { Farmworkers can suffer from pesticide poisoning when they are } \\
\text { applying OPs on crops }\end{array}$ & $\sqrt{ }$ & $\square$ & \\
\hline A5 & OPs can enter the body through inhalation & $\sqrt{ }$ & $\square$ & \\
\hline A6 & $\begin{array}{l}\text { Headache, nausea, cough, and sore throat after applying OPs on } \\
\text { crops are not symptoms of pesticide poisonings }\end{array}$ & $\square$ & $\sqrt{ }$ & \\
\hline A7 & $\begin{array}{l}\text { Vomiting, sweating, chest pain, and diarrhea are the symptoms } \\
\text { of mild pesticide poisoning }\end{array}$ & $\square$ & $\sqrt{ }$ & \\
\hline A8 & $\begin{array}{l}\text { Pesticide poisonings can occur even when farmworkers wash } \\
\text { their hands before eating and drinking }\end{array}$ & $\sqrt{ }$ & $\square$ & \\
\hline A9 & OPs will not cause death unless it is swallowed & $\square$ & $\sqrt{ }$ & 5 \\
\hline A10 & $\begin{array}{l}\text { Psychic disturbances or hallucinations are not symptoms of } \\
\text { pesticide poisonings }\end{array}$ & $\square$ & $\sqrt{ }$ & Г \\
\hline A11 & $\begin{array}{l}\text { Risk of pesticide poisoning can be reduced by washing hands } \\
\text { using clean water and soap before eating and drinking }\end{array}$ & $\sqrt{ }$ & $\square$ & \\
\hline A12 & OP insecticides are the most toxic pesticides & $\sqrt{ }$ & $\square$ & $\square$ \\
\hline
\end{tabular}

Figure SI Knowledge about adverse effects of OPs (a total of I 2 questions). Check only one choice in each question. (Correct answers are checked. Correct answers received 2 points, "don't know" answers received I point, and incorrect answers received 0 point. Minimum and maximum possible total scores were 0 and 24, respectively). Abbreviations: T, true; F, false; DK, don't know; OPs, organophosphate pesticide; OP, organophosphate; Q, question.

\begin{tabular}{|c|c|c|c|c|}
\hline Q\# & Statements & $\mathbf{T}$ & $\mathbf{F}$ & DK \\
\hline B1 & $\begin{array}{l}\text { Clothing contaminated by OPs is not a factor contributing to pesticide } \\
\text { poisonings }\end{array}$ & $\square$ & $\sqrt{ }$ & \\
\hline B2 & Smoking in the field raises the possibility of OPs entering the body & $\sqrt{ }$ & $\square$ & \\
\hline B3 & $\begin{array}{l}\text { Throwing away empty pesticide containers in a farm area is okay } \\
\text { because it will not contaminate the environment }\end{array}$ & $\square$ & $\sqrt{ }$ & \\
\hline B4 & $\begin{array}{l}\text { Unused OPs must be stored in a ventilated room and separated from } \\
\text { pantry or kitchen }\end{array}$ & $\sqrt{ }$ & $\square$ & \\
\hline B5 & $\begin{array}{l}\text { Reentry into a farm area immediately after pesticide spraying without } \\
\text { wearing PPE will increase amount of chemical materials absorbed by a } \\
\text { human body }\end{array}$ & $\sqrt{ }$ & 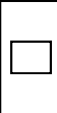 & \\
\hline B6 & $\begin{array}{l}\text { Mixing OPs using bare hands is not harmful and will not cause adverse } \\
\text { effects on human health }\end{array}$ & 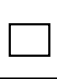 & $\sqrt{ }$ & \\
\hline B7 & $\begin{array}{l}\text { Mostly farmworkers will not suffer from pesticide poisonings even } \\
\text { though they do not wear PPE when working }\end{array}$ & $\square$ & $\sqrt{ }$ & \\
\hline B8 & $\begin{array}{l}\text { Wearing unwashed clothing after working in a farm area can be related } \\
\text { to signs and symptoms of pesticide poisonings }\end{array}$ & $\sqrt{ }$ & 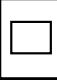 & \\
\hline B9 & $\begin{array}{l}\text { Pesticide poisonings may occur even if farmworkers shower } \\
\text { immediately after working }\end{array}$ & $\sqrt{ }$ & 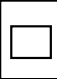 & 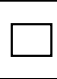 \\
\hline B10 & $\begin{array}{l}\text { Wearing PPE is one of the ways to reduce and to prevent pesticide } \\
\text { exposure during and after working in farm area }\end{array}$ & $\sqrt{ }$ & 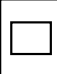 & $\Gamma$ \\
\hline
\end{tabular}

Figure S2 Knowledge about self-protection from OPs exposure (a total of ten questions) Check only one choice in each question. (Correct answers are checked. Correct answers received 2 points, "don't know" answers received I point, and incorrect answers received 0 points. Minimum and maximum possible total scores were 0 and 20 , respectively).

Abbreviations: T, true; F, false; DK, don't know; OPs, organophosphate pesticide; PPE, personal protective equipment; Q, question. 


\begin{tabular}{|c|c|c|c|c|c|c|c|}
\hline Q \# & Statements & $\begin{array}{l}\text { Strongly } \\
\text { disagree }\end{array}$ & Disagree & Neutral & Agree & $\begin{array}{l}\text { Strongly } \\
\text { agree }\end{array}$ & $\begin{array}{l}\text { Direction } \\
\text { of question }\end{array}$ \\
\hline & $\begin{array}{l}\text { Perceived susceptibility (a total of six questions ) } \\
\text { Minimum possible score }=6 \text {; maximum possible score }=30\end{array}$ & & & & & & \\
\hline C1 & Exposure to OPs will not cause any adverse effects to me & $\square$ & & $\square$ & $\square$ & $\square$ & Negative \\
\hline $\mathrm{C} 2$ & Other farmworkers may suffer from pesticide poisoning & $\square$ & & $\square$ & $\square$ & $\square$ & Positive \\
\hline $\mathrm{C} 3$ & Human skin is not a route of OPs to enter the body & $\square$ & & $\square$ & $\square$ & $\square$ & Negative \\
\hline $\mathrm{C} 4$ & OPs are not dangerous for the human body & $\square$ & $\square$ & $\square$ & $\square$ & $\square$ & Negative \\
\hline C5 & OPs are not harmful to the body as long as they are not swallowed & $\square$ & 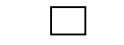 & $\square$ & $\square$ & $\square$ & Negative \\
\hline \multirow[t]{2}{*}{ C6 } & Following pesticide exposure, the pesticide is removed by the liver & $\square$ & $\square$ & $\square$ & $\square$ & $\square$ & Positive \\
\hline & $\begin{array}{l}\text { Perceived severity (a total of four questions) } \\
\text { Minimum possible score }=4 \text {; maximum possible score }=20\end{array}$ & & & & & & \\
\hline C7 & $\begin{array}{l}\text { If the pesticide is on the skin, it will only cause a mild effect and it } \\
\text { will recover soon }\end{array}$ & & & ${ }^{-}$ & $\square$ & $\square$ & Negative \\
\hline $\mathrm{C} 8$ & OPs only cause itchy skin & 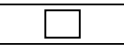 & & 5 & $\square$ & $\square$ & Negative \\
\hline C9 & The effect of pesticide on the body is easily cured & $\mathrm{L}$ & & $\square$ & $\square$ & $\square$ & Negative \\
\hline \multirow[t]{2}{*}{ C10 } & $\begin{array}{l}\text { Redness on the skin after working with OPs in the fields is not } \\
\text { harmful because it is only as an effect of sunlight exposure }\end{array}$ & Г & & 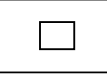 & $\square$ & $\square$ & Negative \\
\hline & $\begin{array}{l}\text { Perceived benefits (total of two questions) } \\
\text { Minimum possible score =2; maximum possible score }=10\end{array}$ & & & & & & \\
\hline C11 & $\begin{array}{l}\text { Use of PPE will protect the body from adverse effects of pesticide } \\
\text { exposure }\end{array}$ & 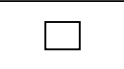 & $\square$ & $\square$ & $\square$ & $\square$ & Positive \\
\hline \multirow[t]{2}{*}{ C12 } & $\begin{array}{l}\text { Although a bit troublesome, wearing PPE is necessary to improve } \\
\text { health }\end{array}$ & 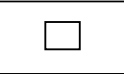 & $\square$ & $\square$ & $\square$ & $\square$ & Positive \\
\hline & $\begin{array}{l}\text { Perceived barriers (total of four questions) } \\
\text { Minimum possible score }=4 \text {; maximum possible score }=20\end{array}$ & & & & & & \\
\hline C13 & Use of PPE is troublesome & L & $\square$ & $\square$ & $\square$ & $\square$ & Negative \\
\hline C14 & PPE is expensive & $\square$ & $\square$ & $\square$ & $\square$ & $\square$ & Negative \\
\hline C15 & Use of PPE causes an uncomfortable feeling in the work & 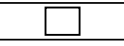 & $\square$ & $\square$ & $\square$ & $\square$ & Negative \\
\hline \multirow[t]{2}{*}{ C16 } & $\begin{array}{l}\text { Following all pesticide safety procedures is not efficient because it } \\
\text { will cause extra time to finish my farmwork }\end{array}$ & 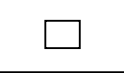 & $\square$ & $\square$ & $\square$ & $\square$ & Negative \\
\hline & $\begin{array}{l}\text { Cues to action (total of four questions) } \\
\text { Minimum possible score }=4 \text {; } \text { maximum possible score }=20\end{array}$ & & & & & & \\
\hline $\mathrm{C} 17$ & A health worker often reminds me to use PPE when I am working & $\square$ & $\square$ & $\square$ & $\square$ & $\square$ & Positive \\
\hline C18 & $\begin{array}{l}\text { My friends were ever sick due to not following pesticide } \\
\text { safety procedures during work }\end{array}$ & $\square$ & $\square$ & $\square$ & $\square$ & $\square$ & Positive \\
\hline C19 & My body often feels itchy after using OPs without wearing PPE & $\square$ & $\square$ & $\square$ & $\square$ & $\square$ & Positive \\
\hline $\mathrm{C} 20$ & I often feel dizzy after spraying OPs on crops & $\square$ & $\square$ & $\square$ & $\square$ & $\square$ & Positive \\
\hline
\end{tabular}

Figure S3 Perceptions about OPs exposure (perceived susceptibility, perceived severity, perceived benefits, perceived barriers, and cues to action). Check only one choice for each question. (Positive-direction questions were scored from I point for "strongly disagree" to 5 points for "strongly agree". Negative-direction questions were scored from I point for "strongly agree" to 5 points for "strongly disagree").

Abbreviations: OPs, organophosphate pesticide; PPE, personal protective equipment; Q, question.

\section{Publish your work in this journal}

Risk Management and Healthcare Policy is an international, peerreviewed, open access journal focusing on all aspects of public health, policy, and preventative measures to promote good health and improve morbidity and mortality in the population. The journal welcomes submitted papers covering original research, basic science, clinical \& epidemio- logical studies, reviews and evaluations, guidelines, expert opinion and commentary, case reports and extended reports. The manuscript management system is completely online and includes a very quick and fair peerreview system, which is all easy to use. Visit http://www.dovepress.com/ testimonials.php to read real quotes from published authors. 